\title{
IN-SITU TENSILE TESTS OF SNOW-PACK LAYERS
}

\author{
By J.B. JAMIESON and C.D. JOHNSTON
}

(Department of Civil Engineering, University of Calgary, Calgary, Alberta T2N 1N4, Canada)

ABSTRACT. During the winter of 1987-88, an average of seven tensile tests was made for each of 66 snow layers in the Rocky Mountains of western Canada. The precision of the mean strength for seven tests, expressed in terms of the coefficient of variation, was $15 \%$ with $90 \%$ confidence. Snow with a faceted micro-structure was approximately half as strong as partly settled or rounded snow of the same density. Notch sensitivity in the strength data and critical strains of $1 \%$ or less indicate that the test fractures were essentially brittle.

\section{INTRODUCTION}

In-situ testing allows the properties of snow to be established with minimal risk of damage to specimens due to extraction from the snow-pack, transportation to a testing laboratory, and setting up in a testing device. It also facilitates the estimation of properties such as tensile strength using specimen cross-sections substantially larger than those feasible in laboratory work, thus reducing the severity of the specimen-size effect of ten prevalent in brittle fractures. However, in-situ testing does not permit control of variables such as snow temperature, ambient air temperature, or humidity. In addition, only rather imprecise control of stress rates is possible with the manual testing techniques presently available for in-situ work.

An in-situ tensile test based on a technique developed by Conway and Abrahamson (1984) was used in the present study. Over 450 tensile tests were made during the winter of 1987-88 in and near the Lake Louise Ski Resort in the Canadian Rocky Mountains.

\section{PREVIOUS IN-SITU STUDIES}

Roch (1966) measured the strength of 37 snow slabs by averaging the results of tensile tests repeated every $50 \mathrm{~mm}$ down the face of crown fractures. For each test, parts of the slab $30-60 \mathrm{~mm}$ thick were gripped with hollow samplers with cross-sections of $2 \times 10^{-3}-3 \times 10^{-2} \mathrm{~m}^{2}$ and uniaxial tension was applied to the samplers with a spring gauge. As discussed subsequently, Roch's tests on these small crosssections resulted in strengths generally higher and more variable than strengths from studies which used larger cross-sections.

Perla (1969) made approximately 250 cantilever beam tests on newly fallen snow. As with other bending tests, areas of maximum tensile stress at failure were small and indeterminate. Tensile strength was estimated by presuming tensile failure at the top of the failure surface; however, the shapes of the fracture surfaces suggested that some fractures may have involved shear effects (McClung, 1979). Also, the estimates of strength for a given density vary widely, in some cases by a factor of ten.

In 38 rolling-cart tests, McClung (1979) applied essentially uniaxial tension to specimens with cross-sections of approximately $0.12 \mathrm{~m}^{2}$. Each specimen was loaded to failure in $1-8 \mathrm{~min}$ by tilting the table under the rollingcart. The results were not affected by the shape of the notches, which indicates that the fractures involved ductility.
Also, the strengths from these uniaxial tests showed less variability than Perla's (1969) cantilever beam tests.

Conway and Abrahamson (1984) developed the "slip-plate" test method shown in Figure 1 and used in the present study. They made 32 tensile tests of snow slabs on avalanche slopes with loading times to failure of up to $15 \mathrm{~s}$ and cross-sections of approximately $0.1 \mathrm{~m}^{2}$.

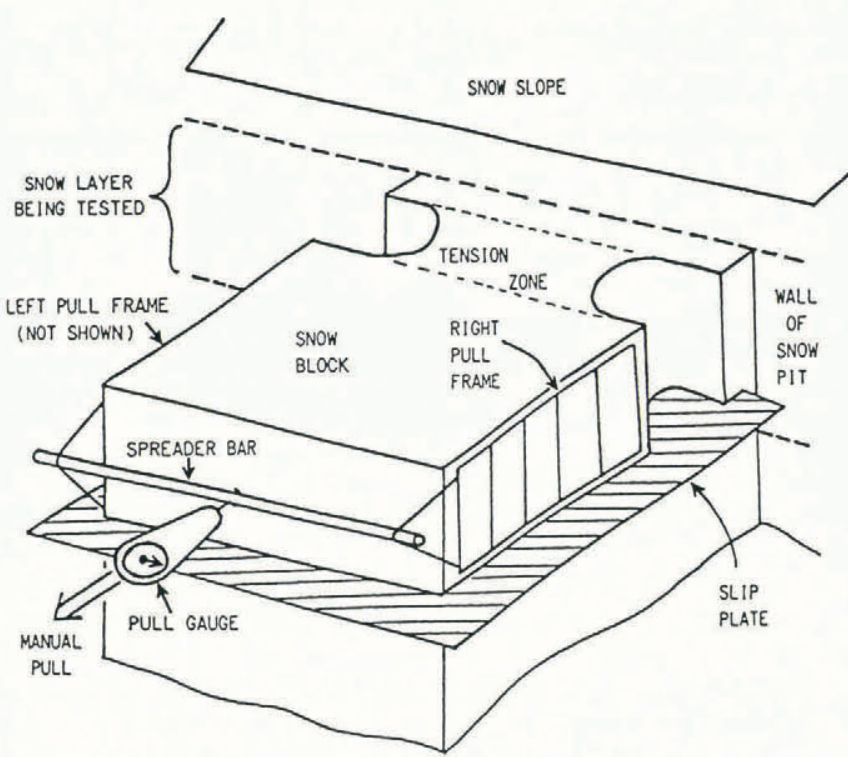

Fig. 1. Slip-plate tensile test with load applied parallel to the slope.

Rosso (1987) measured the strength of 13 snow slabs on steep slopes. For each test, a large trapezoidal block of a snow slab was under-cut parallel to the slope with a snow saw from the lower wider end toward the upper narrower end until it failed in tension. Cross-sections at the point of failure ranged from 0.04 to $0.24 \mathrm{~m}^{2}$. To support the under-cut part of the block and thus minimize bending stresses, a foam pad was trailed behind the saw to fill the gap left by the saw cut. This technique is more timeconsuming than the slip-plate technique and can be done only on steep slopes.

\section{TEST METHOD}

The present study used the test method developed by Conway and Abrahamson (1984), since it applies essentially uniaxial tension to comparatively large cross-sections, requires only $10-15 \mathrm{~min}$ per test, and can be done on level or sloping terrain.

The test method involves isolating a block of snow which remains attached to the up-slope (or back) wall of a pit in the snow-pack as shown in Figure 1. The block is separated from its supporting column of snow by inserting a 
low-friction slip plate, and is gripped on either side by a metal pull frame. The snow attaching the block to the upslope (or back) wall of the snow pit is narrowed by cutting a $50 \mathrm{~mm}$ radius notch behind each pull frame. Cords attach each pull frame to a spreader bar and tension is applied to the mid-point of the spreader bar by a manually operated spring gauge which records the maximum force. The load is applied parallel to the slope and is increased at an approximately constant rate until fracture occurs across the notched tensile zone.

In the present study, the tops of the blocks measured approximately $0.4 \mathrm{~m}$ by $0.4 \mathrm{~m}$ and the blocks were at least $0.1 \mathrm{~m}$ thick. Loading times ranged from 0.5 to $5 \mathrm{~s}$ with a mean of $2.2 \mathrm{~s}$. Friction between the snow and the slip plate was measured by tilting the plate and measuring the "friction angle" at which a snow block on the plate began to slide. Friction angles for the snow blocks on the waxed slip plate ranged from $2^{\circ}$ to $10^{\circ}$ with a mean of $3.6^{\circ}$. These friction angles were obtained by waxing the plate with paste wax for skis. (Coating the plate with a no-stick spray for cooking pans or with a silicon-based spray for ski-bindings resulted in higher friction angles.)

Since the fractures occurred between the notches, the snow in the notched tensile zone was considered to be the specimen. Most specimens in the present study were contained within a single layer of the snow-pack. The grains in each layer were observed under low magnification and classified by predominant grain shape according to UNESCO/IASH/WMO (1970).

\section{EQUIPMENT}

\section{Slip plate}

Plates of $0.6 \mathrm{~mm}$ stainless steel were employed to undercut the snow blocks cleanly and were sufficiently stiff to resist denting and bending under normal handling. The size of each plate was $0.45 \mathrm{~m}$ across, $0.40 \mathrm{~m}$ in the down-slope direction, with $25 \mathrm{~mm}$ stiffening flanges on three sides at right-angles to the surface of the plate. The cutting edge without the flange was sharpened to facilitate gentle insertion under the snow block and minimize the risk of disturbance. Such plates proved adequate for all but extremely weak snow layers where premature failure occasionally occurred during insertion of the slip plate.

\section{Pull frames}

Frames soldered from $25 \mathrm{~mm}$ wide strips of $0.45 \mathrm{~mm}$ stainless steel proved adequately sturdy for testing snow with densities ranging up to $350 \mathrm{~kg} \mathrm{~m}^{-3}$. The length of the frames was $0.28 \mathrm{~m}$ to allow for a $100 \mathrm{~m}$ notched zone at the back of the block and for a $10-20 \mathrm{~mm}$ gap between the snow block and the front flange of the plate. Four equally spaced cross-pieces were soldered in place. To ensure that the depth of the frames approximately spanned the depth of the snow layer being tested, frames with depths of 0.10 , 0.20 , and $0.30 \mathrm{~m}$ were used. The cutting edges of the frames were sharpened to permit penetration of the sides of the snow block with minimal disturbance.

\section{Notching tool}

The blade of this tool consisted of $0.7 \mathrm{~mm}$ stainless steel sheet metal bent into a semi-circle with a $50 \mathrm{~mm}$ radius. During the study of notch sensitivity, which is discussed subsequently, two other notching tools producing notch radii of 10 and $1 \mathrm{~mm}$ were also used.

\section{CALCULATION OF TENSILE STRENGTH}

During each test the following parameters were recorded: maximum pull force $(P)$, loading time to cause fracture $(t)$, length of the block down-slope $\left(l_{\mathrm{b}}\right)$, cross-slope width of the block $\left(w_{\mathrm{b}}\right)$, depth of the block $\left(d_{\mathrm{b}}\right)$, the corresponding dimensions of the tensile zone $(w, d)$, slope angle $(\beta)$, friction angle $(\phi)$ for the snow block on the plate, mean snow density $(\rho)$, and the mass of the frames $\left(m_{\mathrm{f}}\right)$.

Equilibrium conditions just prior to fracture dictate that the average stress is:

$$
\sigma=(W \sin \beta+P-W \tan \phi \cos \beta) /(w d)
$$

in which the weight of the block and frames is

$$
W=\left(l_{\mathrm{b}} w_{\mathrm{b}} d_{\mathrm{b}} \rho+m_{\mathrm{f}}\right) g .
$$

\section{INFLUENCE OF TESTING VARIABLES ON STRENGTH}

\section{Rate effects}

Although manual loading does not allow precise control of the loading rate, the effect of the approximate stress rate on strength was investigated. The test method was repeated eight to 18 times using various loading rates on each of four different layers of rounded grains. The loading rate was maintained approximately constant during each test. However, for each set of tests on a particular layer, a range of loading rates was applied and loading times ranging from $1.5 \mathrm{~s}$ to more than $40 \mathrm{~s}$ were obtained. Approximate stress rates $(\dot{\sigma})$ were calculated from the stress at failure $(\sigma)$ and the loading time $(t)$ :

$$
\dot{\sigma} \approx \sigma / t \text {. }
$$

For each set of repeated tests, Table I shows linear correlation coefficients for the trend between strength and stress rate. Since the two correlations which are significant at the $95 \%$ level are negative, there appears to be a general trend for strength to decrease with an increase in stress

\begin{tabular}{|c|c|c|c|c|}
\hline \multirow[t]{2}{*}{ Date } & Density & $\begin{array}{l}\text { No. of } \\
\text { tests }\end{array}$ & $\begin{array}{l}\text { Correlation } \\
\text { coefficient }\end{array}$ & $\begin{array}{c}\text { Significano } \\
\text { level }\end{array}$ \\
\hline & $\mathrm{kg} \mathrm{m}^{-3}$ & & & \\
\hline 16 Mar 1988 & 203 & 19 & -0.53 & 0.98 \\
\hline 22 Mar 1988 & 295 & 8 & -0.09 & 0.16 \\
\hline 24 Mar 1988 & 298 & 11 & -0.60 & 0.95 \\
\hline 8 Apr 1988 & 228 & 15 & -0.32 & 0.76 \\
\hline
\end{tabular}
rate.

\section{TABLE I. EFFECT OF STRESS RATE ON STRENGTH}

Although Table I uses linear correlation coefficients, the trend between strength and stress rate may not be linear for the range of approximate stress rates used to test these four layers. In Figure 2, strength is plotted against stress rate for the set of 11 tests made on 24 March 1988. For this particular range of stress rates, it appears that a reciprocal relationship between strength and stress rate may be more appropriate than a linear one.

To reduce variability associated with rate effects, tests with loading times greater than $5 \mathrm{~s}$ were screened from the results discussed subsequently.

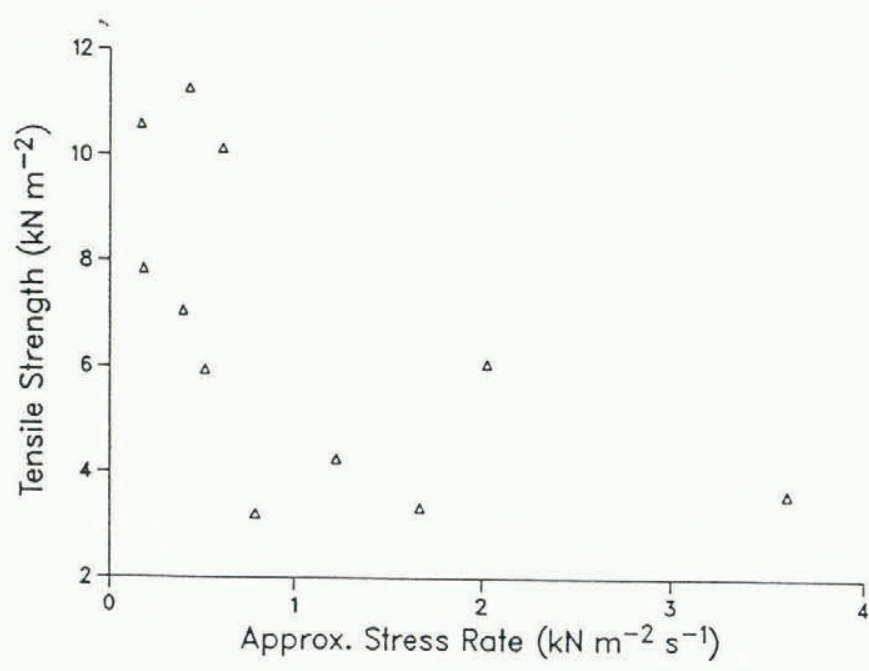

Fig. 2. Effect of stress rate on the strength of a layer of rounded grains with a density of $298 \mathrm{~kg} \mathrm{~m}^{-3}$. 
Test conditions

Snow properties

Replicate number

Loading time to failure*

Slope angle*

Fracture width*

Density*

Temperature

Moisture level $^{\dagger}$

Micro-structure*,

Fracture depth*

Friction angle for snow on plate

Notch shape*, ${ }^{\dagger}$

Plate moved during loading ${ }^{\dagger}$

$*$ Significant at $99 \%$ level.

† Categorical variable.

\section{Notch shape}

To study the effect of notch shape on the results, five different snow layers ranging in density from 184 to $338 \mathrm{~kg} \mathrm{~m}^{-3}$ were tested with 1 and $10 \mathrm{~mm}$ radii notches and with "standard" notches $(50 \mathrm{~mm}$ radius). Fourteen tests with $10 \mathrm{~mm}$ radius notches were each matched with the standard test on the same layer that was physically closest and there was no significant difference in strength between matched tests at the $90 \%$ level. Nineteen tests with $1 \mathrm{~mm}$ radius notches were each paired with the closest standard test on the same snow layer and the mean difference in strength was significant at the $99 \%$ level. The strengths obtained with $1 \mathrm{~mm}$ radius notches were reduced an average of $22 \%$ from tests made with standard notches.

\section{Screening of data}

During the winter of $1987-88$, a total of 555 tests was performed. The effect of various test conditions and fracture characteristics on the results was investigated by a multi-variate regression (Jamieson, unpublished). Several variables, including the location of the test pit, were excluded from the analysis because of strong correlations $(r>0.65)$ with other variables. The list of ten test conditions and 14 fracture characteristics included in the analysis is given in Table II. Many of the listed variables are categorical and each $N$-level categorical variable was represented by $N-1$ dichotomous variables in the regression equation.

As indicated in Table II, density and micro-structure as well as five testing variables and two fracture characteristics were associated with increases in variability at the $99 \%$ level. The two fracture characteristics, fractures at the back of the notched zone and fractures at the front of the notched zone, were associated with a decrease in strength which averaged $11 \%$. Two testing variables (notch radii of $1 \mathrm{~mm}$ and loading times greater than $5 \mathrm{~s}$ ) have already been discussed. The other three testing variables (slope angle and the width and depth of the fracture surface) were accepted as sources of variability in the results as a whole. However, when the cross-sectional area of the notched zone was varied widely for 24 tests of a single layer at a particular study plot, significant size effects were not detected.

The following four factors: notch radii of $1 \mathrm{~mm}$, loading times greater than $5 \mathrm{~s}$, and fractures at the front or back of the notched zone, were considered to be unrelated to the field study of snow strength in terms of material properties, and the 98 tests associated with one or more of these factors were rejected, giving a refined set of 457 tests for studying the tensile strength of snow layers. The following sections of this paper are based on this refined data set.

For a total of 21 tests on four layers, the temperature of the snow specimen was $0^{\circ} \mathrm{C}$ and the free-water content was classified as slightly moist according to the "squeeze test" (UNESCO/IASH/WMO, 1970). The results of these 21 tests are included in the refined data set, since the
Fracture characteristics

Angle between plate and fracture

Fracture at front of notched zone, $e^{*}$

Fracture at back of notched zone*,,

Fracture crosses notched zone $20-40 \mathrm{~mm}$ forward of centre ${ }^{\dagger}$

Fracture crosses notched zone $20-40 \mathrm{~mm}$ behind centre $^{+}$

Fracture angles towards front of one notch ${ }^{+}$

Fracture angles towards back of one notch

Two fracture planes intersect at $10-20^{\circ}$

Two fracture planes intersect at $>20^{\circ}$

Fracture bifurcates

Fracture at back of plate $^{\dagger}$

Cup-shaped fracture

Protuberance on fracture surface ${ }^{\dagger}$

Fracture bypasses a V- or Y-shaped notch ${ }^{\dagger}$

regression analysis did not associate this moisture level with an increase or decrease in strength.

\section{INFLUENCE OF SNOW CHARACTERISTICS ON STRENGTH}

Density and microstructure

Typically, at a particular study site on a given day, the tensile stremgth of a snow layer was measured an average of seven times. Each set of repeated tests is considered to represent a distinct layer because the material properties of snow may change from day to day. The mean strength of each of the 66 sets of repeated tests is plotted against mean density in Figure 3.

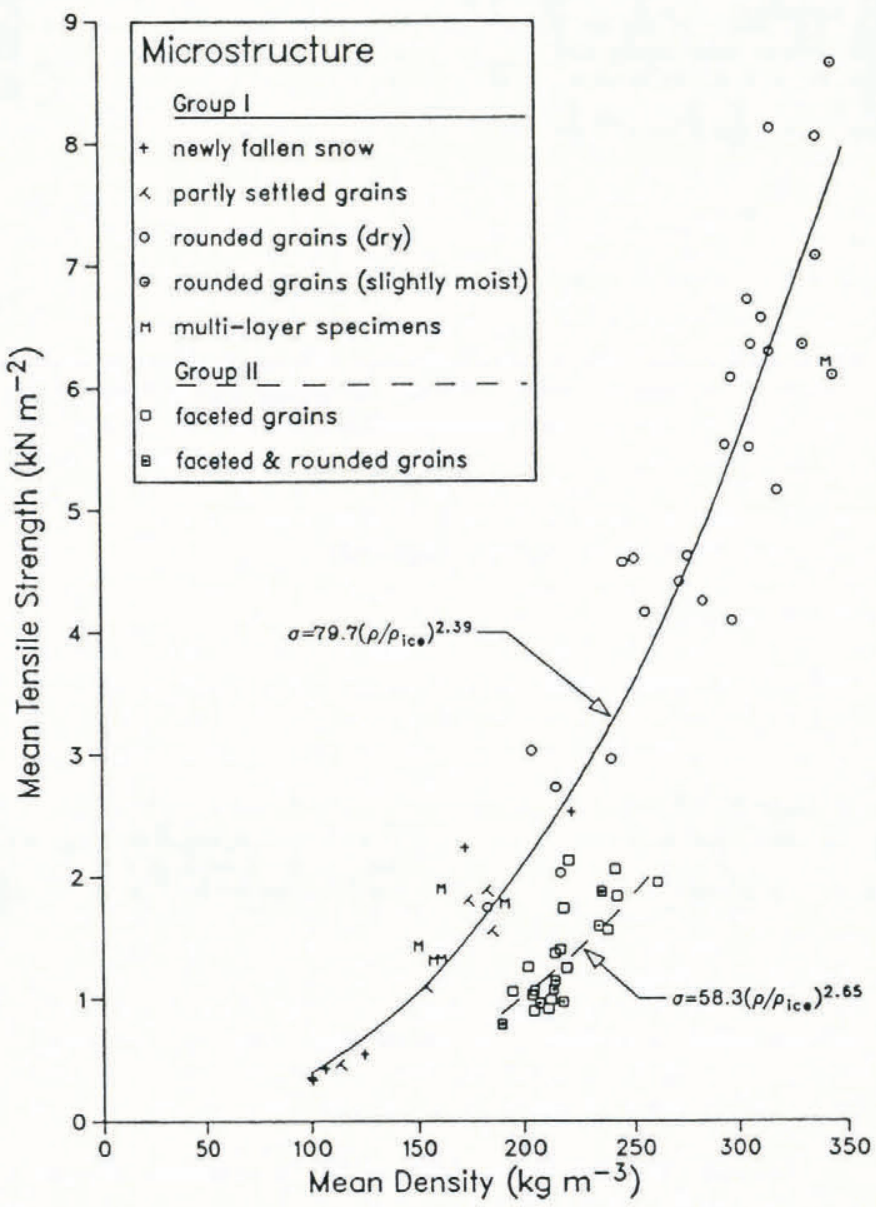

Fig. 3. Dependence of tensile strength on density and microstructure. 
Each layer is placed into one of two groups according to its micro-structure. Group I consists of layers of new snow, partly settled grains or rounded grains with no evidence of melting. Also included in group I are specimens which consist of more than one layer of new, partly settled or rounded grains. Group II consists of layers of faceted grains and of layers of grains which showed both faceting and rounding with no evidence of melting. Separate regression lines for group I and group II micro-structures are also shown in Figure 3. These two lines were obtained by regressing tensile strength $(\sigma)$ on density $(\rho)$ using the empirical equation:

$$
\sigma=A\left(\rho / \rho_{\text {ice }}\right)^{a}
$$

which is analogous to the equation used for shear strength by Perla and others (1982). In Equation (4), $\rho_{\text {ice }}=$ $917 \mathrm{~kg} \mathrm{~m}^{-3}, a$ is a dimensionless constant, and $A$ is a constant with units of $\mathrm{kN} \mathrm{m}^{-2}$. Values of $a$ and $A$ for the two regressions are shown in Table III, along with the range of density for which each group was tested.

\section{TABLE III. REGRESSION COEFFICIENTS AND DENSITY RANGE}

$\begin{array}{lccc}\text { Micro-structure } & A & a & \text { Density } \\ & \mathrm{kN} \mathrm{m}^{-2} & & \mathrm{~kg} \mathrm{~m}^{-3} \\ \text { Group I } & 79.7 & 2.39 & 100-345 \\ \text { Group II } & 58.3 & 2.65 & 190-260\end{array}$

For the density range of $190-260 \mathrm{~kg} \mathrm{~m}^{-3}$, layers with group I and layers with group II micro-structures were tested. For any given density within this range, the strength of the group II layers was approximately half that of the group I layers. However, the results for group II layers may be biased upwards because a number of the weaker specimens broke before the load could be applied.

\section{Comparison with the results of previous in-situ studies}

In Figure 4, strength as a function of density is used to compare the individual test results of the present study with the results of previous in-situ tests from Roch (1966), Perla (1969), McClung (1979), Conway and Abrahamson (1984), and Rosso (1987). Faceted snow, wet snow, and moist snow are excluded from this comparison since there are only three tests on faceted snow (Rosso, 1987) and nine tests on wet snow (McClung, 1979) with which to compare the present results.

Roch (1966) used smaller cross-sections than the other studies and obtained higher and more variable strengths. Perla's (1969) cantilever beam tests, which involved small but indeterminate areas of maximum tensile stress, showed a similar amount of scatter. The remaining studies which applied uniaxial tension to larger cross-sections exhibit less variability.

Below a density of $250 \mathrm{~kg} \mathrm{~m}^{-3}$, the present tensile strengths are consistent with the results of McClung (1979), Conway and Abrahamson (1984), and Rosso (1987). Above $250 \mathrm{~kg} \mathrm{~m}^{-3}$, strengths from the present study appear lower than the few in-situ strengths reported by McClung (1979), Conway and Abrahamson (1984), and Rosso (1987). This reduction in strength is likely due to the rapid loading used in the present study.

\section{Variability}

Coefficients of variation of tensile strength were calculated for each set of more than one test on a particular layer. For the two largest sets ( 30 and 42 replicates), the coefficients of variation were both 0.20 . For the different types of micro-structures, average values of the coefficient of variation ranged from 0.14 for partly settled grains to 0.23 for rounded grains, as shown in Table IV. The apparent increase in the average coefficient of variation for rounded grains compared to the value for other microstructures may not be substantial and is in contrast with Sommerfeld (1973) who reported greater variability of faceted grains compared to other micro-structures.

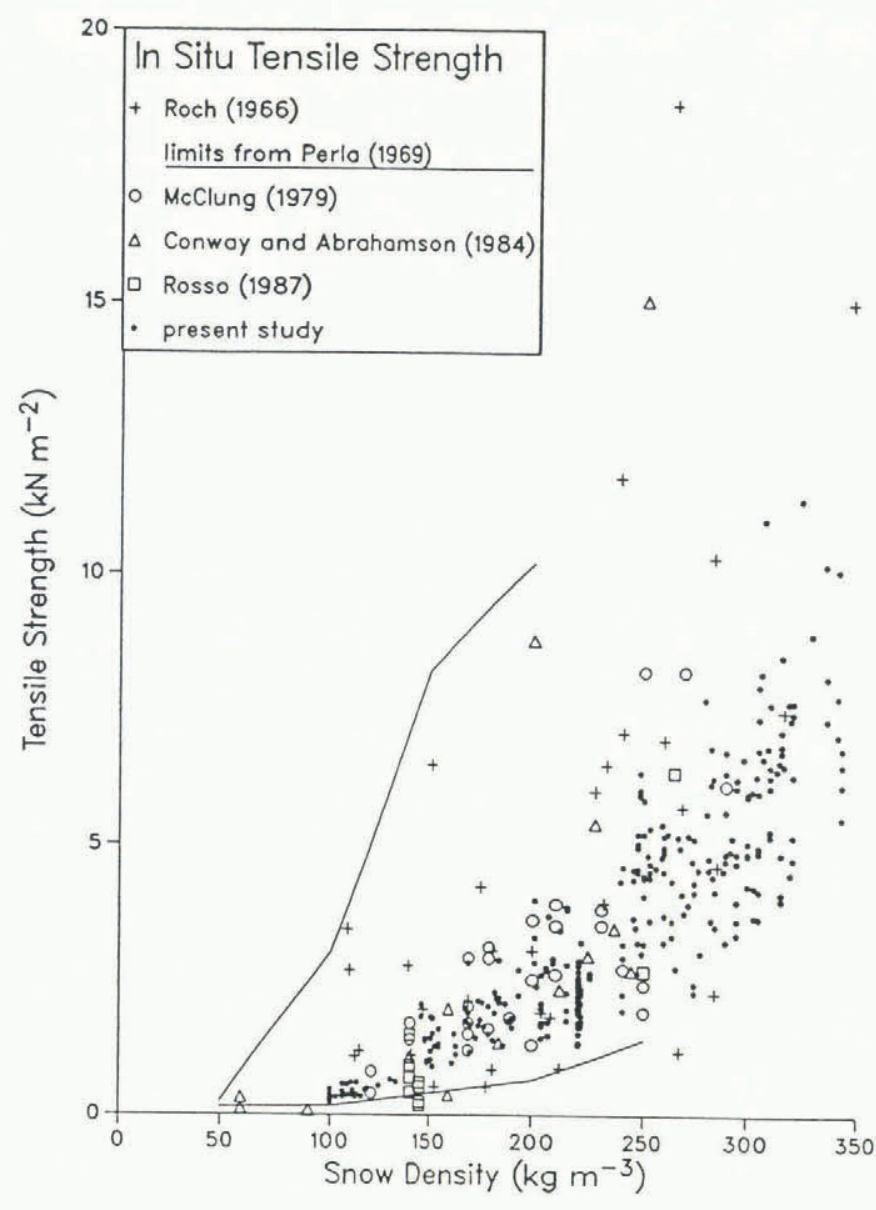

Fig. 4. Comparison with the results of previous in-situ studies. Results for moist or wet snow and for faceted grains are excluded from the comparison. One point from Roch (1966) falls above the top of the figure.

\section{TABLE IV. COEFFICIENTS OF VARIATION OF TENSILE STRENGTH}

Micro-structure No. of sets
of replicates

Newly fallen snow

Partly settled

Rounded

Faceted

Faceted and rounded

5
5
23
15

0.18

0.23

0.18

0.14

\section{Precision}

Appropriate sample sizes for required levels of precision can be estimated from the coefficient of variation (v) of repeated tests on a particular layer of snow. The number of tests $(n)$ which must be averaged to obtain precision $(p)$ a the $1-2 \alpha$ confidence level is given by

$$
n=\left(t_{\alpha, n-1} v / p\right)^{2},
$$

in which $t_{\alpha, n-1}$ is the tabulated value from a Student's $t$ distribution with $n-1$ degrees of freedom and which has a probability of $\alpha$ associated with each tail. Equation (5) is easily solved for $n$ by trial and error and the results for a coefficient of variation of 0.20 are given in Table $\mathrm{V}$.

An average of seven tests was made for each of 66 layers. With $90 \%$ confidence, the mean strength determined from seven replicates will have a precision of $15 \%$.

\section{Critical strain}

Approximate values for the strain just before failure were obtained from a photographic technique which was applied to 15 tests. A scale graduated in $0.5 \mathrm{~mm}$ was placed across one of the two notches and this notch was photographed up to five times per second while the load 
TABLE V. NUMBER OF TESTS FOR REQUIRED PRECISION

Required precision of mean, $p$

$\%$

10

10

15

15
Confidence

level, $1-2 \alpha$

$\%$

$\begin{array}{rr}90 & 13 \\ 95 & 18 \\ 90 & 7 \\ 95 & 10\end{array}$

was increased manually. Loading times to failure for these 15 tests ranged from 1 to $14 \mathrm{~s}$.

The deformation of the tensile zone before failure, as shown by the scale in the photographs, ranged from 0 to $1 \mathrm{~mm}$ with an average of $0.5 \mathrm{~mm}$. Although the accuracy of this technique is only $\pm 0.25 \mathrm{~mm}$, the technique is useful for establishing an upper limit on the deformation. Since the length of the tensile zone is $100 \mathrm{~mm}$, a deformation of $0.5 \mathrm{~mm}$ corresponds to a strain of $0.5 \%$. Thus, the critical strains (just prior to failure) were less than $1 \%$. This limit is used to determine the mode of failure, as discussed in the next section.

\section{Mode of failure}

In the laboratory, Narita (1983) observed that brittle tensile fractures occurred suddenly at strains of $0.8 \%$ or less and exhibited nearly planar fracture surfaces oriented perpendicular to the axial load. In the present study, fracture surfaces were approximately planar and averaged $91.5^{\circ}$ from the axial load, and critical strains were $1 \%$ or less. This agreement between Narita's (1983) laboratory results and the present in-situ results, combined with the notch sensitivity discussed previously, indicates that the fractures in the present study were essentially brittle.

\section{CONCLUSIONS}

1. Tensile tests were made on a total of 43 layers of new, partly settled or rounded grains with no evidence of melting. An average of seven tests was made on each layer. In the density range of $100-345 \mathrm{~kg} \mathrm{~m}^{-3}$, the brittle tensile strength, in $\mathrm{kN} \mathrm{m}^{-2}$, of these layers can be approximated by

$$
\sigma=79.7\left(\rho / \rho_{\text {ice }}\right)^{2.39} \text {. }
$$

An average of six tensile tests was made on each of 23 layers of faceted grains. In eight of these layers, the grains exhibited both faceting and rounding without evidence of melting. In the density range of $190-260 \mathrm{~kg} \mathrm{~m}^{-3}$, the brittle tensile strength of the 23 layers can be approximated by

$$
\sigma=58.3\left(\rho / \rho_{\text {ice }}\right)^{2.65} \text {. }
$$

However, this empirical equation may be biased upwards because a number of weaker specimens of faceted snow broke before the load was applied. In the density range of $190-260 \mathrm{~kg} \mathrm{~m}^{-3}$, layers of faceted grains were approximately half as strong as layers of partly settled or rounded grains.

2. In sheltered study plots, where snow-pack layers show less variability than in areas exposed to wind, coefficients of variation of tensile strength were typically 0.20 . This implies that approximately seven tests are required for a precision of $15 \%$ with $90 \%$ confidence and approximately 13 tests are required to obtain a precision of $10 \%$ with $90 \%$ confidence.

3. An increase in the manually applied stress rate tended to decrease the strength for loading times ranging from 1.5 to $40 \mathrm{~s}$.

For loading times of $14 \mathrm{~s}$ or less, the $100 \mathrm{~mm}$ long tensile zones elongated by $1 \mathrm{~mm}$ or less prior to fracturing. This apparent limit of $1 \%$ on critical strain is in agreement with Narita's (1980) laboratory results for brittle fractures.

4. When tests were made with notches with tip radii of $1 \mathrm{~mm}$, strength was reduced by an average of $22 \%$ compared to tests made with notch radii of $50 \mathrm{~mm}$. Such sensitivity to notch shape is expected for brittle fractures.

\section{ACKNOWLEDGEMENTS}

C. Israelson and D. Norcross of Parks Canada, P.A. Schaerer and D.M. McClung of the National Research Council of Canada, and J. Worrall of Skiing Louise Ltd provided important advice and assistance. Equipment was loaned by C. Stethem of Chris Stethem and Associates, and R.I. Perla of the National Hydrology Research Centre of Canada.

Financial support was provided by Alberta Recreation, Parks and Wildlife Foundation and by the Natural Sciences and Engineering Research Council of Canada.

\section{REFERENCES}

Conway, H. and J. Abrahamson. 1984. Snow stability index. J. Glaciol., 30(106), 321-327.

Jamieson, J.B. Unpublished. In situ tensile strength of snow in relation to slab avalanches. (M.Sc. thesis, University of Calgary, 1988.)

McClung, D.M. 1979. In-situ estimates of the tensile strength of snow utilizing large sample sizes. J. Glaciol., 22(87), 321-329.

Narita, H. 1980. Mechanical behaviour and structure of snow under uniaxial tensile stress. J. Glaciol., 26(94), 275-282.

Narita, H. 1983. An experimental study on tensile fracture of snow. Contrib. Inst. Low Temp. Sci., Ser. A, 32, $1-37$.

Perla, R.I. 1969. Strength tests on newly fallen snow. J, Glaciol., 8(54), 427-440.

Perla, R.I., T.M.H. Beck, and T.T. Cheng. 1982. The shear strength index of alpine snow. Cold Reg. Sci. Technol., 6(1), 11-20.

Roch, A. 1966. Les déclenchements d'avalanches. International Association of Scientific Hydrology Publication 69 (Symposium at Davos 1965 - Scientific Aspects of Snow and Ice Avalanches), 182-195.

Rosso, R.S. 1987. In situ strength measurements of the snowpack. In Proceedings of the International Snow Science Workshop at Lake Tahoe. Homewood, CA, ISSW Workshop Committee, 210-215.

Sommerfeld, R.A. 1973. Statistical problems in snow mechanics. U.S. Dep. Agric. For. Serv. Gen. Techn. Rep. $\mathrm{Rm}-3,29-36$.

UNESCO/IASH/WMO. 1970. Seasonal snow cover. Paris, UNESCO. 